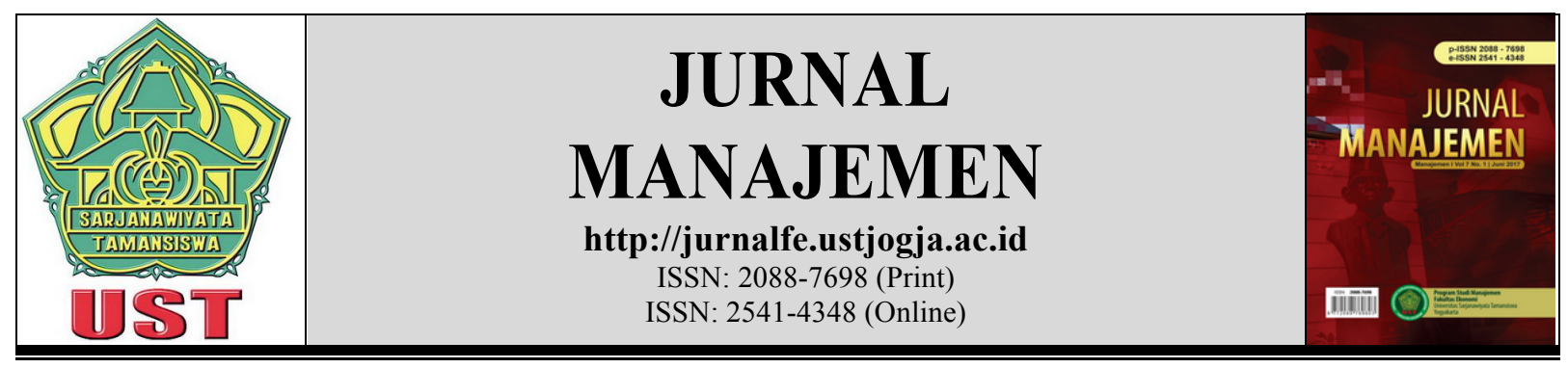

\title{
PENGARUH KEBUTUHAN AKAN PRESTASI, EFIKASI DIRI, KESIAPAN INSTRUMENTASI, DAN FAKTOR DEMOGRAFIS PADA INTENSI KEWIRAUSAHAAN MAHASISWA PEMENANG PROGRAM MAHASISWA WIRAUSAHA
}

\author{
Ignatius Soni Kurniawan \\ Universitas Sarjanawiyata Tamansiswa Yogyakarta \\ Korespondensi: Soni_kurniawan@ustjogja.ac.id
}

\begin{tabular}{|c|c|}
\hline Informasi Naskah & Abstrak \\
\hline Diterima: & This research adopted Indarti dan Rostiani (2008) research \\
\hline 20 Desember 2017 & framework. It aimed to examine influencing need for achievement, \\
\hline Revisi: & self eficacy, instrumental readiness and demographics variable \\
\hline 27 Desember 2017 & (gender, educational background, job experience) partially to \\
\hline Terbit: & entrepreneural intention. The sample of the reserach was \\
\hline 30 Desember 2017 & university student the winner of Program Mahasiswa Wirausaha \\
\hline Kata Kunci: Need for & located in Kopertis 7 Surabaya. The sample was taken applying a \\
\hline Achievement, Self & non-probability method with a purposive sampling technique. The \\
\hline Eficacy, Instrumental & data collecting was carried out using direct survey technique with \\
\hline Readiness, Gender, & questionnaires. The data were analyzed by multiple regression \\
\hline Educational & statistic. The result of the analysis reveals that self eficacy, gender, \\
\hline Background, Job & and educational background partially influencing entrepreuneural \\
\hline Experience, & intention. Whereas need for achievement, instrumental readiness \\
\hline $\begin{array}{l}\text { Intrepreneural } \\
\text { Intention }\end{array}$ & and job experience not influencing entrepreneural intention. \\
\hline
\end{tabular}

\section{PENDAHULUAN}

Menurut Direktorat Pembelajaran dan Kemahasiswaan Direktorat Pendidikan Tinggi (2012), tingginya jumlah sarjana menganggur dapat terjadi karena (1) sistem pembelajaran di Perguruan Tinggi cenderung diarahkan agar mahasiswa cepat lulus dan mendapat pekerjaan bukan menciptakan lapangan kerja, (2) mind set mahasiswa adalah menjadi pencari kerja bukan pencipta lapangan kerja, dan (3) aktivitas kewirausahaan (entrepreneurial activity) masih rendah. Dimulai pada tahun anggaran 2009, Pemerintah melalui Direktorat Jenderal Pendidikan Tinggi, Kementerian Pendidikan Nasional meluncurkan Program Mahasiswa Wirausaha (PMW) untuk dilaksanakan dan dikembangkan oleh perguruan tinggi. PMW bertujuan 
menumbuhkembangkan wirausaha-wirausaha baru yang berpendidikan tinggi dan memiliki pola pikir pencipta lapangan kerja, serta membentuk model pendidikan kewirausahaan dan kelembagaannya di perguruan tinggi (Direktorat Pembelajaran dan Kemahasiswaan Direktorat Pendidikan Tinggi, 2012). Hasil akhirnya, diharapkan terjadi penurunan lulusan pendidikan tinggi yang mengganggur. Fasilitas yang diberikan kepada pemenang PMW meliputi pendidikan dan pelatihan kewirausahaan, magang, penyusunan rencana bisnis, dukungan permodalan, dan pendampingan usaha. Manfaat PMW bagi mahasiswa meliputi a) memperoleh kesempatan untuk meningkatkan softskill; b) memperoleh kesempatan terlibat secara langsung dalam kegiatan bisnis; c) menumbuhkan jiwa bisnis (sense of business) sehingga memiliki keberanian untuk memulai dan mengembangkan usaha dengan modal yang diberikan dan pendampingan secara terpadu (Direktorat Pembelajaran dan Kemahasiswaan Direktorat Pendidikan Tinggi, 2012).

Strategi pendidikan PMW yang diarahkan pada pembentukan softskill agar berperilaku sesuai karakter wirausaha (Direktorat Pembelajaran dan Kemahasiswaan Direktorat Pendidikan Tinggi, 2012) didasarkan pada tiga teori Drucker (1985). Tiga teori tersebut meliputi: 1) teori yang mengutamakan peluang usaha (teori ekonomi); 2) teori yang mengutamakan tanggapan orang terhadap peluang (teori sosiolog dan psikolog), dan; 3) teori yang mengutamakan hubungan antara perilaku wirausaha dengan hasilnya (teori perilaku). Penggunaan teori tersebut memiliki arti bahwa kewirausahaan dapat dipelajari, dilatihkan dan dikuasai. Lulusan perguruan tinggi dapat memilih kerja dan berkarir dibidang kewirausahaan.

Penggunaan teori perilaku tidak dapat dipisahkan dari aspek motivasi berwirausaha atau entrepreneurial intention, artinya kewirausahaan dapat dipelajari dan dikuasai, dan kewirausahaan dapat menjadi pilihan kerja dan pilihan karir bagi lulusan perguruan tinggi, apabila memang dalam diri mahasiswa ada intensi untuk menjadi seorang entrepreneur. Seberapa besar intensi kewirausahaan mahasiswa tentunya akan dipengaruhi atau ditentukan oleh beberapa faktor. Oleh karena itu perlu diketahui faktor-faktor yang mempengaruhi motivasi mahasiswa untuk menjadi entrepreneur atau intensi menjadi entrepreneur.

Penelitian terdahulu menunjukkan kebutuhan akan prestasi (McClelland, 1961; Sengupta dan Debnath, 1994; Green et al., 1996), efikasi diri (Giles dan Rea, 1999; Indarti, 2004) dan kesiapan instrumen (Indarti dan Rostiani, 2008) merupakan prediktor signifikan intensi kewirausahaan. Beberapa penelitian menemukan hasil yang saling kontradiksi. Indarti dan Rostiani (2008) menemukan bahwa kebutuhan akan prestasi tidak mempengaruhi intensi kewirausahaan sedangkan efikasi diri mempengaruhi intensi kewirausahaan mahasiswa di Indonesia dan Norwegia serta kesiapan instrumen terbukti mempengaruhi intensi mahasiswa di Norwegia. Hasil penelitian Segal (2005) menyatakan bahwa efikasi diri terbukti tidak mempengaruhi intensi berwirausaha. Penelitian Nastiti et al., (2010) menemukan kebutuhan akan prestasi, efikasi diri, dan kesiapan instrumen mempengaruhi intensi kewirausahaan mahasiswa China.

\section{KAJIAN PUSTAKA DAN HIPOTESIS Intensi Kewirausahaan}

Intensi kewirausahaan adalah proses pencarian informasi yang dapat digunakan untuk mencapai tujuan pembentukan suatu usaha (Katz dan Gartner, 1988). Indikator pengukuran intensi kewirausahaan adalah sebagai berikut (Ramayah \& Harun, 2005): 1) saya akan memilih karir sebagai seorang wirausahawan; 2) saya akan memilih karir sebagai karyawan dalam suatu 
perusahaan/organisasi; 3) saya lebih suka menjadi wirausahawan daripada menjadi karyawan di suatu perusahaan/organisasi.

\section{Kebutuhan Akan Prestasi}

Kebutuhan akan prestasi adalah suatu kesatuan watak yang memotivasi seseorang dalam menghadapi tantangan untuk mencapai kesuksesan dan keunggulan (Lee, 1997). Indikator pengukuran variabel kebutuhan akan prestasi adalah sebagai berikut (McClelland (1976): 1) saya akan melakukan yang paling baik pada tugas yang sulit yang berhubungan dengan studi dan pekerjaan saya; 2) saya akan berusaha keras untuk memperbaiki performa kerja sebelumnya; 3) saya akan mencari tambahan tanggung jawab pada pekerjaan yang diberikan kepada saya; 4) saya akan berusaha untuk melakukan yang lebih baik dibandingkan dengan teman saya.

\section{Efikasi Diri}

Efikasi diri adalah kepercayaan seseorang atas kemampuan diri sendiri untuk menyelesaikan suatu pekerjaan (Bandura, 1977). Indikator pengukuran variabel efikasi diri adalah sebagai berikut (Gaddam, 2008): 1) saya memiliki keterampilan kepemimpinan yang dibutuhkan untuk menjadi seorang wirausahawan; 2) saya memiliki kematangan mental untuk memulai menjadi seorang wirausahawan; 3) saya adalah orang yang dapat dipercaya oleh orang lain; 4) saya memiliki kemampuan dapat menyelesaikan pekerjaan dengan baik.

\section{Kesiapan Instrumentasi}

Kesiapan instrumentasi adalah bagian dari faktor lingkungan yang meliputi akses kepada modal, jaringan sosial, dan ketersediaan informasi (Indarti, 2004). Indikator pengukuran variabel kesiapan instrumentasi adalah sebagai berikut (Indarti dan Rokhima, 2008): 1) saya memiliki akses kepada modal untuk mulai menjadi wirausahawan; 2) saya memiliki jaringan sosial yang bagus yang dapat dimanfaatkan ketika saya memutuskan untuk menjadi seorang wirausahawan; 3) saya memiliki akses terhadap informasi saat mulai menjadi seorang wirausahawan; 4) saya memiliki kemampuan mengatur modal dengan baik.

\section{Faktor Demografi}

Faktor demografi meliputi jender (Mazzarol et al. 1999), latar belakang pendidikan (Sinha, 1996), dan pengalaman kerja (Kolvereid, 1996). Jender menunjuk pada jenis kelamin, yaitu laki-laki atau perempuan. Latar belakang pendidikan menunjukkan kesesuaian pendidikan yang diperolehnya dengan usaha yang akan dilakukan. Pengalaman kerja menunjuk pada pengalaman individu dalam merasakan dunia kerja yang sesungguhnya. Indikator pengukuran variabel demografi adalah sebagai berikut (Indarti dan Rokhima, 2008): 1) jenis kelamin (a. laki-laki atau b. perempuan) 2) fakultas (a. ekonomi atau b. non ekonomi) 3) pengalaman kerja (a. belum pernah, b. sektor swasta, c. sektor publik/pemerintah, d. kedua sektor tersebut).

\section{Kebutuhan Akan Prestasi dan Intensi Kewirausahaan}

Menjadi karyawan pada perusahaan atau instansi milik orang lain merupakan pilihan yang lebih banyak diambil mahasiswa di Indonesia daripada menjadi wirausahawan. Namun dengan tingginya pengangguran terdidik yang tinggi karena keterbatasan kesempatan kerja, mahasiswa dapat mengarahkan usaha dengan membuka usaha sendiri. Melimpahnya jumlah tenaga kerja mengakibatkan lemahnya daya tawar calon tenaga kerja terhadap perusahaan, yang diwujudkan pada rendahnya gaji dan fasilitas bagi karyawan baru. Hal ini akan memberikan gambaran yang tidak menyenangkan bagi mahasiswa untuk melamar untuk menjadi karyawan di perusahaan lain. Kebutuhan mahasiswa untuk mendapatkan gaji dan prestasi yang lebih baik justru akan terbuka bila memilih menjadi wirausahawan. Menjadi wirausahawan yang berhasil 
merupakan prestasi yang dapat diraih mahasiswa ketika lulus. Kebutuhan mencapai prestasi merupakan pendorong mahasiswa untuk memiliki niat berwirausaha. Semakin tinggi prestasi yang harus dicapai maka semakin tinggi tantangan yang dihadapi, dan kebutuhan untuk mencapai prestasi juga semakin besar. Kebutuhan berprestasi yang diwujudkan dengan menjadi pemenang PMW diharapkan menjadi bukti adanya intensi kewirausahaan pada mahasiswa pemenang PMW. Penelitian Sengupta dan Debnath (1994) di India menunjukkan kebutuhan prestasi memiliki pengaruh pada kewirausahaan yang sukses. Kebutuhan akan prestasi memiliki pengaruh pada intensi kewirausahaan (Green et al., 1996).

H1. Kebutuhan akan prestasi memiliki pengaruh positif pada intensi kewirausahaan.

\section{Efikasi Diri dan Intensi Kewirausahaan}

Kebutuhan akan prestasi yang berhasil dipenuhi dengan berhasil menjadi pemenang PMW diharapkan menciptakan kepercayaan diri mahasiswa atas kemampuan dirinya. Mahasiswa pemenang PMW akan lebih percaya diri dibanding mahasiswa lain yang tidak memenangkan kompetisi. Kepercayaan diri atas kemampuan diri sendiri atau efikasi diri ini diharapkan menjadi unsur pembentuk minat mahasiswa menjadi wirausahawan. Mahasiswa yang lebih percaya diri melihat dirinya mampu menjadi wirausahawan akan lebih berminat menjadi wirausahawan dibanding mahasiswa lain yang tidak mempunyai kepercayaan diri karena anggapan ketidakmampuan diri. Efikasi diri diharapkan memiliki pengaruh pada intensi kewirausahaan. Penelitian sebelumnya membuktikan efikasi diri merupakan faktor yang membentuk intensi kewirausahaan (Bandura, 1986, Betz dan Hacket, 1986). Intensi kewirausahaan akan semakin kuat bila efikasi diri semakin tinggi.

H2. Efikasi diri memiliki pengaruh positif pada intensi kewirausahaan.

\section{Kesiapan Instrumentasi dan Intensi Kewirausahaan}

Modal merupakan hal yang paling sering menjadi hambatan dalam mendirikan usaha. Mahasiswa PMW diharapkan tidak mengalami hambatan modal yang terlalu besar lagi seiring dengan hibah modal yang diberikan bagi pemenang PMW. Selain modal, mahasiswa pemenang PMW akan mendapat pelatihan dari universitas dan pelatihan dari pemerintah serta jaringan bisnis pendukung. Ketersediaan informasi dan jaringan sosial mahasiswa pemenang PMW diharapkan semakin meningkat dengan berbagai pelatihan, pendampingan serta dukungan dari universitas dan pemerintah selama pelaksanaan usaha.

Semakin baik kesiapan instrumentasi maka semakin tinggi intensi kewirausahaan. Penelitian Mazzarol et al., (1999) menyatakan akses kepada modal merupakan penentu intensi kewirausahaan. Penelitian Singh dan Krishna (1994) menyatakan wirausahawan memiliki karakter untuk mengumpulkan informasi. Diharapkan mahasiswa yang bersedia mengumpulkan informasi terkait usaha diharapkan memiliki intensi kewirausahaan. Ketersediaan karena kemauan mahasiswa membangun jaringan sosial sebagai jalur untuk mendapat sumber daya dalam menjalankan usaha merupakan faktor penentu intensi kewirausahaan (Kristiansen, 2003).

H3. Kesiapan instrumentasi memiliki pengaruh positif pada intensi kewirausahaan.

\section{Jender dan Intensi Kewirausahaan}

Mahasiswa laki-laki pemenang PMW memiliki pilihan menjalankan usaha yang lebih luas terutama dalam melewati batasan fisik dibanding mahasiswi pemenang PMW. Mahasiswi kemungkinan akan menghindar memilih pekerjaan yang membutuhkan usaha fisik lebih besar. Penggunaan waktu di malam hari untuk melakukan usaha juga mungkin lebih terbatas dilakukan mahasiswi daripada mahasiswa laki-laki terutama berkaitan dengan faktor keamanan dan kenyamanan. Jumlah mahasiswa laki-laki yang memiliki keberanian untuk menghadapi tantangan dimungkinkan akan lebih besar, dibanding jumlah mahasiswi yang menyukai 
tantangan. Penelitian membuktikan bahwa laki-laki cenderung lebih menyukai membuka usaha dibanding perempuan (Mazzaro et al., 1999). Penelitian lain juga mempertegas bahwa perempuan memiliki intensi kewirausahaan yang lebih rendah dibanding laki-laki (Kolvereid, 1996). Mahasiswa diharapkan memiliki intensi kewirausahaan lebih tinggi dibanding mahasiswi.

Hipotesis 4: Intensi kewirausahaan berhubungan dengan jender; laki-laki mempunyai intensi kewirausahaan lebih tinggi.

\section{Latar Belakang Pendidikan dan Intensi Kewirausahaan}

Mahasiswa pemenang PMW dengan latar belakang pendidikan dari fakultas ekonomi akan menerima pendidikan lebih intensif mengenai seluk beluk perusahaan dibanding mahasiswa dari fakultas non ekonomi. Mahasiswa yang menerima pendidikan dengan kurikulum dibidang perusahaan dan kewirausahaan akan memiliki pemahaman yang lebih dibanding mahasiswa yang tidak mendapat pendidikan di bidang perusahaan dan kewirausahaan. Pemahaman yang mendalam mengenai kewirausahaan diharapkan akan memunculkan wirausahawan. Penelitian Sinha (1996) dan Lee (1997) membuktikan bahwa latar belakang pendidikan menjadi penentu intensi kewirausahaan. Literatur menunjukkan mahasiswa Norwegia dengan latar belakang dari fakultas ekonomi lebih memiliki intensi kewirausahaan dibanding mahasiswa dari fakultas non ekonomi (Indarti dan Rokhima, 2008). Mahasiswa pemenang PMW dari fakultas ekonomi diharapkan lebih memiliki intensi kewirausahaan dibanding mahasiswa dari fakultas non ekonomi.

Hipotesis 6: Mahasiswa yang berlatar belakang pendidikan ekonomi memiliki intensi kewirausahaan yang lebih tinggi dibandingkan mereka yang berlatar belakang pendidikan non ekonomi.

\section{Pengalaman Kerja dan Intensi Kewirausahaan}

Mahasiswa pemenang PMW yang memiliki latar belakang pengalaman kerja akan memiliki pengetahuan yang cukup dalam bidang kewirausahaan. Pengalaman kerja merupakan bentuk hasil pendidikan praktek. Praktek bekerja secara langsung memberikan pengalaman emosi yang berbeda dibanding ketika belajar teori. Penelitian terdahulu menemukan bahwa orang yang memiliki pengalaman kerja mempunyai intensi kewirausahaan lebih tinggi dibanding mereka yang tidak pernah bekerja sebelumnya (Kolvereid, 1996). Temuan Indarti dan Rokhima (2008) pada mahasiswa Norwegia menunjukkan mahasiswa dengan pengalaman kerja memiliki intensi kewirausahaan yang besar dibanding yang tidak memiliki pengalaman kerja.

Hipotesis 7: Mahasiswa yang memiliki pengalaman kerja memiliki intensi kewirausahaan yang lebih tinggi dibandingkan dengan mereka yang tidak memiliki pengalaman kerja.

\section{METODE PENELITIAN}

Unit analisis dalam penelitian ini adalah individu. Populasi dalam penelitian ini adalah mahasiswa pemenang PMW Kopertis VII tahun 2012. Sampel dalam penelitian ini adalah mahasiswa pemenang PMW yang menghadiri Diklat PMW yang diselenggarakan STIE Perbanas pada 27 Juli 2012 (Tabel 1). Metode penarikan sampel yang digunakan adalah pengambilan sampel nonprobabilitas. Teknik pengambilan sampel menggunakan judgement atau purposive sampling. Sampel yang diambil hanya yang memenuhi kriteria yaitu menghadiri Diklat PMW di STIE Perbanas 27 Juli 2012. Besarnya sampel yang digunakan dalam penelitian ini adalah 60 buah, mengacu pada rule of thumb yang dikemukakan oleh Roscoe (1975) dalam 
Sekaran (2002) bahwa sampel sejumlah 30-500 adalah cukup bagi kebanyakan penelitian.

Tabel 1. Populasi dan Sampel

\begin{tabular}{|c|c|c|c|c|}
\hline No & $\begin{array}{c}\text { Perguruan Tinggi } \\
\text { Populasi }\end{array}$ & Kota & Sampel & Proposal Usaha \\
\hline 1 & IKIP PGRI & Madiun & 4 & $\begin{array}{l}\text { Usaha "Warung Bakso Pelangi" } \\
\text { rendah kolesterol sebagai } \\
\text { Peluang Usaha Mahasiswa IKIP } \\
\text { PGRI Madiun }\end{array}$ \\
\hline 2 & STIKES Nahdlatul Ulama & Tuban & 3 & $\begin{array}{l}\text { Produksi dan Pemasaran Batik } \\
\text { Gedog "SWAKA TARUNA } \\
\text { RONGGOLAWE" }\end{array}$ \\
\hline 3 & Unika. Widaya Mandala & Surabaya & 6 & $\begin{array}{l}\text { Produksi dan Pemasaran } \\
\text { Katering Anak "Healthy Kids" } \\
\text { Pembuatan Minuman Kesehatan } \\
\text { Berbahan Baku Teh dan Jahe } \\
\text { dengan Merek Huangli }\end{array}$ \\
\hline 4 & Unika. Widya Mandala & Madiun & 4 & $\begin{array}{l}\text { Produksi dan Pemasaran } \\
\text { Brownies Edulis Organik, Sehat } \\
\text { dan Lezat } \\
\text { "SULE" (Susu Tempe Kedelai) } \\
\text { Pengganti Susu Formula }\end{array}$ \\
\hline 5 & Univ. Islam & Lamongan & 2 & $\begin{array}{l}\text { Pembesaran dan Pemasaran } \\
\text { Ikan Gurami Silapit (secara } \\
\text { intensif di lahan sempit) } \\
\text { Laba Kampus: Layanan Bahasa } \\
\text { ETP dan TOEFL/TOEIC } \\
\text { Preparation (Program } \\
\text { berkelanjutan dari program } \\
\text { PMW 2009 English course \& } \\
\text { Translation) }\end{array}$ \\
\hline 6 & Univ. Muhammadiyah & Ponorogo & 3 & $\begin{array}{l}\text { Pembuatan Tahu Nigarin } \\
\text { Berbasis Industri Inovatif } \\
\text { (Technopreneur) }\end{array}$ \\
\hline 7 & STIBA "Satya Widya" & Surabaya & 3 & $\begin{array}{l}\text { Pembuatan dan Pemasaran "Le } \\
\text { Vetement Crayon" }\end{array}$ \\
\hline 8 & $\begin{array}{l}\text { Stikes Ngudia Husada } \\
\text { Madura }\end{array}$ & Bangkalan & 4 & Baby Bamboo Fresh (BBF) \\
\hline 9 & STKIP PGRI & Ngawi & 3 & $\begin{array}{l}\text { Produksi dan Pemasaran } \\
\text { Dendeng Berbahan Jantung } \\
\text { Pisang }\end{array}$ \\
\hline 10 & STKIP PGRI & Ponorogo & 3 & $\begin{array}{l}\text { Kreasi Kaos Kancil dari Bahan } \\
\text { Perca Kain Kaos }\end{array}$ \\
\hline & & & & Es Krim Mengkudu Aneka Rasa \\
\hline 11 & Sekolah Tinggi Teknik & Surabaya & 2 & Marchandhise Khas Suramadu \\
\hline
\end{tabular}




\begin{tabular}{lllcl}
\hline No & \multicolumn{1}{c}{$\begin{array}{c}\text { Perguruan Tinggi } \\
\text { Populasi }\end{array}$} & Kota & Sampel & \multicolumn{1}{c}{ Proposal Usaha } \\
\hline 12 & Univ. Muhammadiyah & Sidoarjo & 0 & $\begin{array}{l}\text { Krupuk Ampas Tahu Bayam } \\
\text { dan Wortel }\end{array}$ \\
\hline 13 & Univ. Muhammadiyah & Gresik & 3 & $\begin{array}{l}\text { Snack Rempah Sehat Bervarian } \\
\text { Rasa dan Rupa Cara Baru } \\
\text { Makan Jamu }\end{array}$ \\
\hline 14 & STIE Perbanas & Surabaya & 8 & $\begin{array}{l}\text { Kebab Jamur sebagai Alternatif } \\
\text { Penurunan Kolesterol } \\
\text { Balaring "Balado Keripik Daun } \\
\text { Ginseng" }\end{array}$ \\
\hline 15 & STKIP PGRI & Pacitan & 1 & Inovasi pengolahan Ikan Marlin \\
\hline 16 & STP Satya Widya & Surabaya & 4 & $\begin{array}{l}\text { Usaha Kuliner "My Potatoes" } \\
\text { Pengembangan Wirausaha }\end{array}$ \\
\hline 17 & Univ. PGRI Adi Buana & Surabaya & 2 & $\begin{array}{l}\text { Kerajinan Furniture Berbasis } \\
\text { Green Material }\end{array}$ \\
\hline 18 & Univ. PGRI Ronggolawe & Tuban & 5 & $\begin{array}{l}\text { Aneka Rasa Olahan Jamur } \\
\text { Tiram Krispy "Murphy" }\end{array}$ \\
\hline 19 & Univ. Islam Darul Ulum & Lamongan & 0 & $\begin{array}{l}\text { Pembuatan Telur Asin tanpa } \\
\text { Bau Amis }\end{array}$ \\
\hline 20 & Univ. Muhammadiyah & Surabaya & 0 & $\begin{array}{l}\text { Fresh Organic Kunyit Asam } \\
\text { Original }\end{array}$ \\
\hline & & Jumlah & $\mathbf{6 0}$ & \\
\hline
\end{tabular}

Sumber: Data primer diolah

\section{ANALISIS DATA DAN PEMBAHASAN Karakteristik Responden}

Data mengenai karakteristik responden dalam penelitian ini secara lengkap disajikan dalam Tabel 2. Karakteristik menunjukkan hal yang menarik yaitu mahasiswi lebih mendominasi daripada mahasiswa, demikian juga asal fakultas dari non ekonomi lebih banyak dibanding dari fakultas ekonomi. Responden sebagian besar berpengalaman kerja, baik di sektor swasta ataupun publik, atau keduanya. Demikian juga meskipun mengikuti PMW, sebagian besar responden mempertimbangkan untuk tetap melamar kerja.

Tabel 2. Karakteristik Responden

\begin{tabular}{llcc}
\hline Dimensi & Kategori & $\begin{array}{c}\text { Responden } \\
(\boldsymbol{n})\end{array}$ & $\begin{array}{c}\text { Persentase } \\
(\boldsymbol{\%})\end{array}$ \\
\hline \hline \multirow{2}{*}{ Jenis Kelamin } & a. Laki-Laki & 26 & 43,33 \\
& b. Perempuan & 34 & 56,67 \\
\hline \multirow{2}{*}{ Fakultas } & a. Ekonomi & 22 & 34,38 \\
& b. Non Ekonomi & 38 & 59,38 \\
\hline \multirow{2}{*}{ Pengalaman Kerja } & a. Belum pernah & 25 & 39,06 \\
& b. Sektor swasta & 31 & 51,56 \\
\hline
\end{tabular}




\begin{tabular}{|c|c|c|c|}
\hline Dimensi & Kategori & $\begin{array}{c}\text { Responden } \\
(n)\end{array}$ & $\begin{array}{c}\text { Persentase } \\
(\%)\end{array}$ \\
\hline & $\begin{array}{ll}\text { c. } & \text { Sektor } \\
\text { publik/pemerintah }\end{array}$ & 3 & 4,69 \\
\hline & d. Kedua sektor tersebut & 1 & 1.56 \\
\hline Penerimah Hibah & a. Ya & 60 & 100,00 \\
\hline PMW & b. Tidak & 0 & 0 \\
\hline \multirow{4}{*}{$\begin{array}{l}\text { Rencana Setelah } \\
\text { Lulus }\end{array}$} & a. Melamar pekerjaan & 4 & 6,25 \\
\hline & $\begin{array}{l}\text { b. Menciptakan } \\
\text { pekerjaan }\end{array}$ & 13 & 20,31 \\
\hline & c. Keduanya & 43 & 67,19 \\
\hline & Jumlah & 60 & 100,00 \\
\hline
\end{tabular}

Sumber: Data primer diolah

\section{Uji Kualitas Data}

Hasil penelitian ini diolah dari data yang dikenai expectation maximization sebagai pengganti missing value jawaban responden. Indikator Kebutuhan akan pencapaian no 3 dan indikator Intensi Kewirausahaan no 2 dihilangkan untuk meningkatkan reliabilitas. Tabel 3 menunjukkan bahwa hasil pengujian reliabilitas setelah penghilangan kedua indikator tersebut memiliki Cronbach's Alpha 0,515 - 0,673. Mengacu Nunally (1978) nilai koefisien lebih dari 0,5 dapat diterima, hal ini berarti kuesioner adalah reliabel dan menghasilkan jawaban seseorang terhadap pernyataan adalah konsisten dari waktu ke waktu. Pengujian validitas isi dilakukan dengan melakukan korelasi bivariate antara masing-masing skor indikator dengan konstruk. Tabel 3 menunjukkan indikator dengan hasil korelasi Pearson yang signifikan (sig. 2-tailed kurang dari 0,05) atau indikator pertanyaan adalah valid.

Tabel 3 Hasil Pengujian Validitas dan Reliabilitas

\begin{tabular}{llcc}
\hline \multicolumn{1}{c}{ Indikator } & $\begin{array}{c}\text { Pearson } \\
\text { Correlation }\end{array}$ & $\begin{array}{c}\text { Sig. } \\
(\mathbf{2 -} \\
\text { tailed })\end{array}$ & $\begin{array}{c}\text { Cronbach's } \\
\text { Alpha }\end{array}$ \\
\hline $\begin{array}{l}\text { Kebutuhan Akan } \\
\text { Prestasi }\end{array}$ & & & \\
\hline $\begin{array}{l}\text { 1. Kebutuhan akan } \\
\text { prestasi 1 }\end{array}$ & 0,775 & 0,000 & \\
2. Kebutuhan akan & 0,677 & 0,000 & 0,515 \\
$\quad \begin{array}{l}\text { prestasi 2 } \\
\text { 3. Kebutuhan akan } \\
\text { prestasi 3 }\end{array}$ & 0,667 & 0,000 & \\
\hline Efikasi Diri & & & \\
\hline 1. Efikasi diri 1 & 0,716 & 0,000 & \\
2. Efikasi diri 2 & 0,733 & 0,000 & 0,673 \\
3. Efikasi diri 3 & 0,721 & 0,000 & \\
4. Efikasi diri 4 & 0,670 & 0,000 & \\
\hline Kesiapan Instrumentasi & & & \\
\hline
\end{tabular}




\begin{tabular}{|c|c|c|c|}
\hline Indikator & $\begin{array}{c}\text { Pearson } \\
\text { Correlation }\end{array}$ & $\begin{array}{c}\text { Sig. } \\
\text { (2- } \\
\text { tailed) }\end{array}$ & $\begin{array}{c}\text { Cronbach's } \\
\text { Alpha }\end{array}$ \\
\hline $\begin{array}{l}\text { 1. Kesiapan } \\
\text { instrumentasi } 1\end{array}$ & 0,615 & 0,000 & \multirow{4}{*}{0,620} \\
\hline $\begin{array}{l}\text { 2. Kesiapan } \\
\text { instrumentasi } 2\end{array}$ & 0,707 & 0,000 & \\
\hline $\begin{array}{l}\text { 3. Kesiapan } \\
\text { instrumentasi } 3\end{array}$ & 0,726 & 0,000 & \\
\hline $\begin{array}{l}\text { 4. Kesiapan } \\
\text { instrumentasi } 4\end{array}$ & 0,685 & 0,000 & \\
\hline \multicolumn{4}{|l|}{ Intensi Kewirausahaan } \\
\hline $\begin{array}{l}\text { 1. Intensi kewirausahaan } \\
1\end{array}$ & 0,801 & 0,000 & \multirow{2}{*}{0,517} \\
\hline $\begin{array}{l}\text { 2. Intensi Kewirausahaan } \\
3\end{array}$ & 0,840 & 0,000 & \\
\hline
\end{tabular}

Sumber: Data primer diolah (Lampiran 3)

\section{Uji Asumsi Klasik}

Agar dapat dilakukan uji regresi maka variabel demografi jender, asal fakultas, dan pengalaman bekerja dianggap sebagai variabel dummy dengan kode 0 dan 1 . Jender laki-laki diberi kode 1 dan kode 0 untuk perempuan. Latar belakang pendidikan ekonomi diberi kode 1 dan non-ekonomi dan bisnis dengan kode 0 . Pengalaman bekerja diberi kode 1 dan belum bekerja dengan kode 0 . Tabel 4 menunjukkan hasil uji asumsi klasik, pada uji multikolonieritas nilai tolerance tidak menunjukkan ada variabel dependen yang memiliki nilai kurang dari 0,10 , nilai VIF tidak ada yang melebihi 10 atau tidak ada mulitikolonieritas antar variabel independen dalam model regresi. Tabel 4 menunjukkan verifikasi heteroskedastisitas Park test memiliki koefisien parameter beta tidak signifikan secara statistik $(>0,05)$, konsisten dengan scatterplots yang memperlihatkan titik-titik menyebar secara acak serta tersebar baik di atas maupun di bawah angka 0 pada sumbu Y. Tabel 4 menunjukkan besarnya nilai Kolmogorov-Smirnov Z 0,608 dan tidak signifikan pada 0,05 , konsisten dengan histogram yang masih mengikuti kurva lonceng dan normal probability-plot yang mengikuti arah garis diagonal atau artinya data residual berdistribusi normal.

Tabel 4 Hasil Uji Asumsi Klasik

\begin{tabular}{|c|c|c|c|c|c|c|}
\hline \multicolumn{2}{|c|}{ Variabel } & \multirow{2}{*}{$\begin{array}{c}\text { Collinearity } \\
\text { Statistics }\end{array}$} & \multicolumn{2}{|c|}{ Park Test } & \multicolumn{2}{|c|}{$\begin{array}{l}\text { Kolmogorov- } \\
\text { Smirnov Test }\end{array}$} \\
\hline Independen & Dependen & & Beta & Sig. & $\begin{array}{l}\text { Kolmo- } \\
\text { gorov- } \\
\text { Smirno } \\
\text { v Z }\end{array}$ & Sig. \\
\hline $\begin{array}{l}\text { Kebutuhan } \\
\text { Akan Prestasi }\end{array}$ & \multirow{4}{*}{$\begin{array}{c}\text { Intensi } \\
\text { Kewirausaha } \\
\text { an }\end{array}$} & 1,433 & 0,088 & 0,581 & \multirow{4}{*}{0,608} & \multirow{4}{*}{$\begin{array}{c}0,85 \\
3\end{array}$} \\
\hline Efikasi diri & & 1,462 & 0,163 & 0,315 & & \\
\hline $\begin{array}{l}\text { Kesiapan } \\
\text { Instrumentasi }\end{array}$ & & 1,270 & $\begin{array}{c}- \\
0,085\end{array}$ & 0,571 & & \\
\hline Jender & & 1,123 & 0,019 & 0,895 & & \\
\hline
\end{tabular}




\begin{tabular}{|c|c|c|c|c|c|c|}
\hline \multicolumn{2}{|c|}{ Variabel } & \multirow{2}{*}{$\begin{array}{c}\begin{array}{c}\text { Collinearity } \\
\text { Statistics }\end{array} \\
\text { VIF }\end{array}$} & \multicolumn{2}{|c|}{ Park Test } & \multirow{2}{*}{\multicolumn{2}{|c|}{\begin{tabular}{cc}
\multicolumn{2}{c}{ Kolmogorov- } \\
Smirnov Test \\
Kolmo- \\
gorov- \\
Smirno Sig. \\
v Z
\end{tabular}}} \\
\hline Independen & Dependen & & Beta & Sig. & & \\
\hline $\begin{array}{l}\text { Latar } \\
\text { Belakang } \\
\text { Pendidikan }\end{array}$ & & 1,069 & 0,158 & 0,257 & & \\
\hline $\begin{array}{l}\text { Pengalaman } \\
\text { kerja }\end{array}$ & & 1,169 & $\begin{array}{c}- \\
0,026\end{array}$ & 0,857 & & \\
\hline
\end{tabular}

Sumber: Data primer diolah

\section{Pengujian Hipotesis \\ Pengujian Hipotesis 1}

Berdasarkan hasil analisis data (Tabel 5) tampak bahwa nilai t hitung untuk variabel kebutuhan akan prestasi adalah sebesar 0,015. Nilai tersebut berada pada probabilitas 0,988 > 0,05 sehingga diinterpretasikan bahwa variabel kebutuhan akan prestasi tidak mempunyai pengaruh yang signifikan terhadap intensi kewirausahaan. Oleh karenanya hipotesis 1 dalam penelitian ini yang berbunyi: Kebutuhan akan prestasi memiliki pengaruh positif pada intensi kewirausahaan ditolak.

Temuan ini tidak mendukung hasil penelitian sebelumnya (Sengupta dan Debnath, 1994, Green et al., 1996). Kebutuhan akan prestasi diduga tidak berpengaruh karena mahasiswa pemenang PMW melihat pencapaian justru dengan bekerja pada perusahaan lain. Profil responden setelah lulus memperlihatkan mayoritas mahasiswa pemenang PMW cenderung mengambil pilihan melamar dan menciptakan pekerjaan sekaligus $(67,19 \%)$. Pilihan ini dianggap pilihan yang paling aman daripada menganggur dan masih adanya pandangan masyarakat serta orang tua mahasiswa yang melihat prestasi dari prestise perusahaan yang berhasil dimasuki mahasiswa. Demikian juga temuan sejenis dari Indarti dan Rokhima (2008) dengan responden mahasiswa di Indonesia menunjukkan tidak ada bukti bahwa kebutuhan akan berprestasi berpengaruh positif terhadap intensi. Ukuran-ukuran prestasi lebih mengedepankan keberhasilan bekerja di perusahaan dan bukan menjadi wirausaha (Indarti dan Rokhima, 2008).

\section{Pengujian Hipotesis 2}

Berdasarkan hasil analisis data (Tabel 5) tampak bahwa nilai t hitung untuk variabel efikasi diri adalah sebesar 2,210. Nilai tersebut berada pada probabilitas 0,031<0,05 sehingga diinterpretasikan bahwa variabel efikasi diri mempunyai pengaruh yang signifikan terhadap intensi kewirausahaan. Oleh karenanya hipotesis 2 dalam penelitian ini yang berbunyi: efikasi diri memiliki pengaruh positif pada intensi kewirausahaan diterima.

Temuan ini mendukung penelitian Bandura (1986), Betz dan Hacket (1986) serta Nastiti et al., (2010). Efikasi diri yang dibentuk dari pandangan kemampuan diri dalam memimpin, kematangan mental dan rasa percaya diri merupakan faktor penyebab intensi mahasiswa pemenang PMW untuk berwirausaha. Nilai beta 0,252 yang positif juga mempertegas hubungan searah antara efikasi diri dengan intensi kewirausahaan. Semakin tinggi efikasi yang ada dalam diri responden semakin besar niat atau intensi untuk melakukan wirausaha demikian juga semakin rendah efikasi diri maka semakin rendah intensi kewirausahaannya. 


\section{Tabel 5 Uji $t$}

\section{Coefficients"}

\begin{tabular}{|c|c|c|c|c|c|}
\hline \multirow[b]{2}{*}{ Model } & \multicolumn{2}{|c|}{$\begin{array}{l}\text { Unstandardized } \\
\text { Coefficients }\end{array}$} & \multirow{2}{*}{$\begin{array}{c}\begin{array}{c}\text { Standardized } \\
\text { Coefficients }\end{array} \\
\text { Beta }\end{array}$} & \multirow[b]{2}{*}{$t$} & \multirow[b]{2}{*}{ Sig. } \\
\hline & $B$ & Std. Error & & & \\
\hline 1 (Constant) & 1.617 & 2.151 & & .752 & .455 \\
\hline $\begin{array}{l}\text { Total Kebutuhan Akan } \\
\text { Prestasi }\end{array}$ & .002 & .134 & .002 & .015 & .988 \\
\hline Total Efikasi Diri & .252 & .114 & .318 & 2.210 & .031 \\
\hline $\begin{array}{l}\text { Total Kesiapan } \\
\text { Instrumentasi }\end{array}$ & .112 & .097 & .153 & 1.145 & .258 \\
\hline Jenis Kelamin & .716 & .341 & .265 & 2.098 & .041 \\
\hline Fakultas & .709 & .342 & .255 & 2.072 & .043 \\
\hline Pengalaman Kerja & -.117 & .350 & -.043 & -.335 & .739 \\
\hline
\end{tabular}

a. Dependent Variable: Total Intensi Kewirausahaan

Sumber: Data primer diolah.

\section{Pengujian Hipotesis 3}

Berdasarkan hasil analisis data (Tabel 5) tampak bahwa nilai t hitung untuk variabel kesiapan instrumentasi adalah sebesar 1,145. Nilai tersebut berada pada probabilitas $0,258>$ 0,05 sehingga diinterpretasikan bahwa kesiapan instrumentasi tidak mempunyai pengaruh yang signifikan terhadap intensi kewirausahaan. Oleh karenanya hipotesis 3 dalam penelitian ini yang berbunyi: Kesiapan instrumentasi memiliki pengaruh positif pada intensi kewirausahaan ditolak. Berarti kesiapan instumentasi tidak mempunyai pengaruh signifikan terhadap intensi kewirausahaan.

Temuan ini tidak mendukung penelitian sebelumnya (Mazzarol et al., 1999 dan Nastiti et al., 2010). Instrumen meliputi akses untuk mendapatkan modal, jaringan sosial dan akses informasi bukanlah faktor yang menyebabkan intensi kewirausahaan mahasiswa pemenang PMW. Meskipun mahasiswa pemenang PMW akan menerima modal usaha dan pelatihan kewirausahaan bersama kelompok pemenang dari universitas lain, hal itu belum menciptakan intensi kewirausahaan. Dukungan perguruan tinggi asal untuk meningkatkan ketersediaan instrumentasi perlu dilakukan agar dapat memotivasi mahasiswa. Hasil ini selaras dengan temuan Indarti dan Rokhima (2008) bahwa kesiapan instrumentasi tidak signifikan mempengaruhi intensi kewirausahaan mahasiswa Indonesia.

\section{Pengujian Hipotesis 4}

Berdasarkan hasil analisis data (Tabel 5) tampak bahwa nilai t hitung untuk variabel jender adalah sebesar 1,145. Nilai tersebut berada pada probabilitas $0,041<0,05$ sehingga diinterpretasikan bahwa jender mempunyai pengaruh yang signifikan terhadap intensi kewirausahaan. Oleh karenanya hipotesis 4 dalam penelitian ini yang berbunyi: jender berhubungan dengan intensi kewirausahaan; laki-laki mempunyai intensi kewirausahaan lebih tinggi diterima. 
Temuan bahwa mahasiswa pemenang PMW laki-laki lebih memiliki intensi kewirausahaan dibandingkan mahasiswa perempuan mendukung penelitian sebelumnya (Mazzaro et al, 1999) dan bertentangan dengan temuan Indarti dan Rokhima (2008). Crosstabulation data menghasilkan rencana setelah lulus, laki-laki lebih banyak yang ingin menciptakan pekerjaan $(34,6 \%)$ dibanding wanita $(11,8 \%)$. Wanita juga memperlihatkan keinginan melamar pekerjaan yang lebih tinggi $(8,8 \%)$ dibanding laki-laki $(3,8 \%)$.

\section{Pengujian Hipotesis 5}

Berdasarkan hasil analisis data (Tabel 5) tampak bahwa nilai t hitung untuk variabel Jender adalah sebesar 2,072. Nilai tersebut berada pada probabilitas 0,043<0,05 sehingga diinterpretasikan bahwa latar belakang pendidikan mempunyai pengaruh yang signifikan terhadap intensi kewirausahaan. Oleh karenanya hipotesis 4 dalam penelitian ini yang berbunyi: mahasiswa yang berlatar belakang pendidikan ekonomi dan bisnis memiliki intensi kewirausahaan yang lebih tinggi dibandingkan mereka yang berlatar belakang pendidikan nonekonomi dan bisnis diterima.

Temuan ini mendukung penelitian Sinha (1996) bahwa latar belakang pendidikan merupakan faktor pembentuk intensi kewirausahaan. Mahasiswa pemenang PMW dari fakultas ekonomi sangat dimungkinkan memiliki sumber daya pengetahuan dan keterampilan yang sesuai untuk memulai usaha. Kurikulum dan pendidikan kewirausahaan yang diberikan pada mahasiswa fakultas ekonomi sangat relevan untuk meningkatkan intensi kewirausahaan mahasiswa.

\section{Pengujian Hipotesis 6}

Berdasarkan hasil analisis data (Tabel 5) tampak bahwa nilai t hitung untuk variabel pengalaman kerja adalah sebesar $-0,335$. Nilai tersebut berada pada probabilitas $0,739>0,05$ sehingga diinterpretasikan bahwa pengalaman kerja tidak mempunyai pengaruh yang signifikan terhadap intensi kewirausahaan. Oleh karenanya hipotesis 4 dalam penelitian ini yang berbunyi: Mahasiswa yang memiliki pengalaman kerja memiliki intensi kewirausahaan yang lebih tinggi dibandingkan dengan mereka yang belum pernah bekerja sebelumnya ditolak.

Temuan ini tidak mendukung penelitian sebelumnya (Kolvereid, 1996). Pengalaman kerja mahasiswa pemenang PMW ternyata tidak menciptakan motivasi untuk melakukan wirausaha. Besar kemungkinan selama bekerja responden merasakan kenyamanan sehingga tidak menjadi faktor yang menciptakan intensi kewirausahaan. Hasil ini sejalan dengan penelitian Indarti dan Rostiana (2008) bahwa pengalaman kerja mahasiswa Indonesia bukan faktor penyebab intensi kewirausahaan.

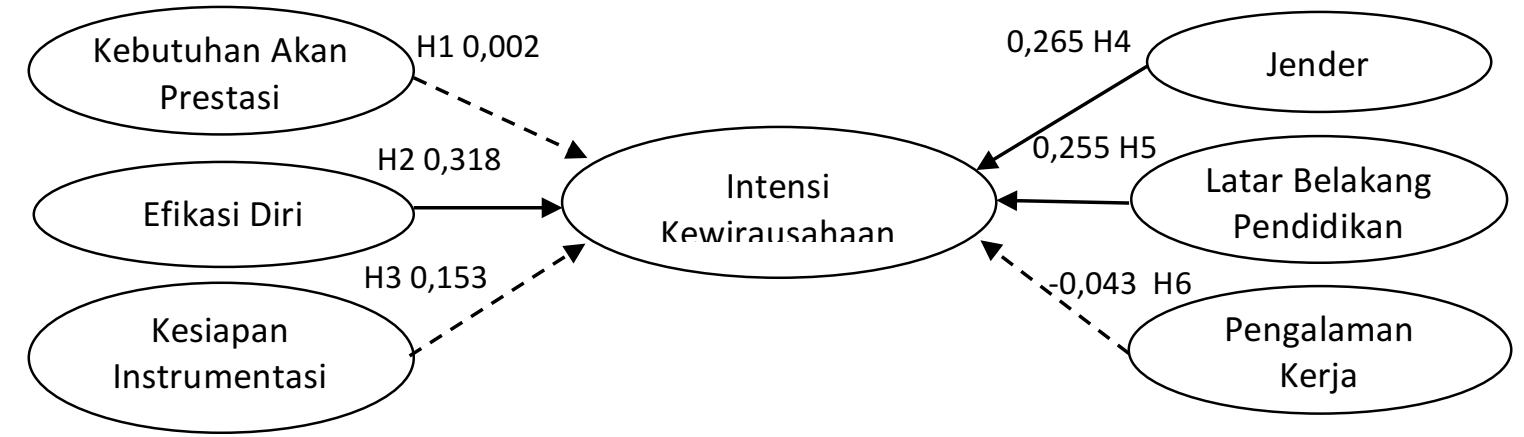

Ket.: $-\rightarrow$ Tidak berpengaruh

$\longrightarrow$ Berpengaruh signifikan 


\section{PENUTUP}

Hasil penelitian ini menemukan pengaruh signifikan efikasi diri, jender, dan latar belakang pendidikan yang secara parsial berpengaruh pada intensi kewirausahaan. Penelitian ini diharapkan dapat memberikan pertimbangan bagi para praktisi (yaitu dosen pengampu dan pendamping kewirausahaan, serta, pengambil kebijakan di bidang pendidikan kewirausahaan) dengan meningkatkan intensi kewirausahaan mahasiswa melalui pengembangan efikasi diri, pendampingan kewirausahaan yang lebih intensif pada mahasiswa perempuan dan pendidikan kewirausahaan pada fakultas non ekonomi.

Penelitian ini menunjukkan bahwa efikasi diri adalah variabel yang dominan mempengaruhi intensi kewirausahaan, diikuti jender, dan latar belakang pendidikan. Temuan ini menambah literatur yang menunjukkan pengaruh tidak signifikan secara parsial dari kebutuhan akan prestasi, kesiapan instrumentasi, dan variabel demografi pengalaman kerja pada intensi kewirausahaan. Penelitian lebih lanjut perlu mengakomodasi variabel bebas lain untuk memahami intensi kewirausahaan dengan populasi yang lebih luas pada program kewirausahaan bentuk lainnya.

\section{REFERENSI}

Bandura, A., 1977. Social Learning Theory. Englewood Cliffs, New Jersey: Prentice Hall.

Bandura, A., 1986. The Social Foundation of Tought and Action. Englewood Cliffs, NJ: Prentice-Hall.

Betz, N.E. dan Hackett, 1986. "Application of Self-efficacy Theory to Understanding Career Choice Behavior". Journal of Social Clinical and Phsycology 4: 279-289.

Direktorat Pembelajaran dan Kemahasiswaan Direktorat Pendidikan Tinggi, 2012. Panduan $\begin{array}{lll}\text { Program Mahasiswa } & \text { Wirausaha } & \end{array}$ https://www.google.com/url?q=http://www.dikti.go.id/files/Belmawa/Pedoman Progra m_Mahasiswa_Wirausaha_(PMW).pdf\&sa=U\&ei=MMtrUPLgOqyOmQX87YGYDg \&ved $=0 \mathrm{CAcQFjAA \& client}=$ internal-udscse\&usg=AFQjCNGZImvdZjfmqyIQ K4Py-I7H11A7Q. Diakses tanggal 3 Oktober 2012.

Drucker, 1985. Innovation and Entrepreneurship. New York: Harper and Row.

Gaddam, S., 2008. "Identifying the Relationship Between Behavioral Motives and Entrepreneurial Intentions: An Empirical Study Based Participations of Business Management Students". The Icfaian Journal of Management Research 7: 35-5.

Giles, M. dan Rea, 1999. Career Self-Efficacy: An Application of the Theory of Planned Behaviour. Journal of Occupational and Organizational Psychology 72 (3): 393-398.

Green, R., David, Dent, dan Tyshkovsky, 1996. "The Russian Entrepreneur: a Study of Psychological Characteristics". International Journal of Entrepreneurial Behaviour \& Research, 2 (1): 49-58.

Indarti, N. dan Rokhima R., 2008. "Intensi Kewirausahaan Mahasiswa: Studi Perbandingan Antara Indonesia, Jepang dan Norwegia”. Jurnal Ekonomika dan Bisnis Indonesia, 23 (4).

Indarti, N., 2004. "Factors Affecting Entrepreneurial Intentions Among Indonesian Students". Jurnal Ekonomi dan Bisnis 19 (1): 57-70.

Katz, J., dan W. Gartner, 1988. "Properties of Emerging Organizations". Academy of Management Review 13 (3): 429-441. 
Kolvereid, L., 1996. "Prediction of Employment Status Choice Intentions". Entrepreneurship Theory and Practice 21 (1): 47-57.

Kristiansen, S., B. Furuholt, dan F. Wahid, 2003. "Internet Cafe Entrepreneurs: Pioneers in Information Dissemination in Indonesia". The International Journal of Entrepreneurship and Innovation 4 (4): 251-263.

Lee, J., 1997. "The Motivation of Women Entrepreneurs in Singapore". International Journal of Entrepreneurial Behaviour and Research 3 (2): 93-110.

Mazzarol, T., T. Volery, N. Doss, dan V. Thein, 1999. "Factors Influencing Small Business Start-ups". International Journal of Entrepreneurial Behaviour and Research 5 (2): 4863.

McClelland, D., 1961. The Achieving Society. Princeton, New Jersey: Nostrand.

McClelland. J. L., 1976. "Preliminary Letter Identification in The Perception of Words and Nonwords". Journal of Experimental Psychology: Human Perception and Performance (2): 80-91.

Nastiti, T., Nur I. dan Rokhima R., 2010. "Minat Berwirausaha Mahasiswa Indonesia dan China". Manajemen \& Bisnis, 9 (2).

Nunally, J. C., 1978. Psychometric Theory. New York: McGraw-Hill.

Ramayah, T., \& Harun, 2005. "Entrepreneurial Intention Among the Student of Universiti Sains Malaysia (USM)". International Journal of Management and Entrepreneurship 1: 8-20.

Segal, G., \& Borgia, dan Schoenfeld, 2005. The Motivation to Become an Entreprenur. International Journal of Entrepreneurial Behavior \& Research 11, 42-57.

Sekaran, U., 2000. Research Methods for Business: A Skill-Building Approach. Fourth edition. United States of America: John Wiley \& Sons, Inc.

Sengupta, S. K. dan S. K. Debnath, 1994. "Need for Achievement and Entrepreneurial Success: A Study of Entrepreneurs in Two Rural Industries in West Bengal". The Journal of Entrepreneurship 3 (2): 191-204.

Singh, K.A., dan K. V. S. M. Krishna, 1994. "Agricultural Entrepreneurship: The Concept and Evidence". Journal of Entrepreneurship 3 (1): 97-111.

Sinha, T. N., 1996. "Human Factors in Entrepreneurship Effectiveness". Journal of Entrepreneurship 5 (1): 23-29. 